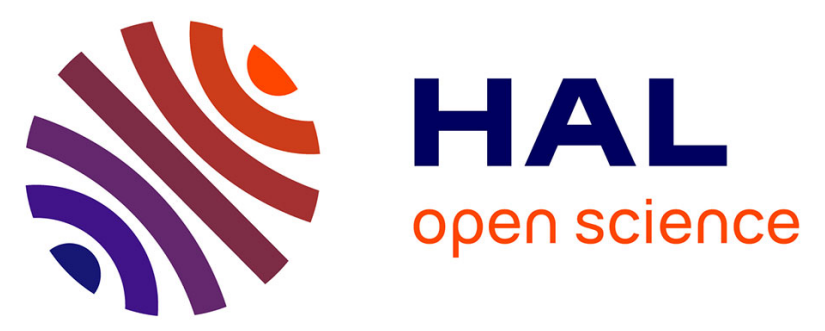

\title{
Major bleeding with antithrombotic agents a 2012-2015 study using the French nationwide Health Insurance database linked to emergency department records within five areas - rationale and design of SACHA study
} Jacques Bouget, Frédéric Balusson, Lucie-Marie Scailteux, Maxime Maignan, Pierre-Marie Roy, Erwan L'Her, Laure Pavageau, Emmanuel Nowak

\section{To cite this version:}

Jacques Bouget, Frédéric Balusson, Lucie-Marie Scailteux, Maxime Maignan, Pierre-Marie Roy, et al.. Major bleeding with antithrombotic agents a 2012-2015 study using the French nationwide Health Insurance database linked to emergency department records within five areas - rationale and design of SACHA study. Fundamental \& Clinical Pharmacology, 2019, 33 (4), pp.443-462. 10.1111/fcp.12444 . hal-02020939

HAL Id: hal-02020939

https://hal-univ-rennes1.archives-ouvertes.fr/hal-02020939

Submitted on 4 Mar 2019

HAL is a multi-disciplinary open access archive for the deposit and dissemination of scientific research documents, whether they are published or not. The documents may come from teaching and research institutions in France or abroad, or from public or private research centers.
L'archive ouverte pluridisciplinaire HAL, est destinée au dépôt et à la diffusion de documents scientifiques de niveau recherche, publiés ou non, émanant des établissements d'enseignement et de recherche français ou étrangers, des laboratoires publics ou privés. 
DR. LUCIE-MARIE SCAILTEUX (Orcid ID : 0000-0001-7047-9107)

Article type : Original Article

\section{Major bleeding with antithrombotic agents: a 2012-2015 study using the French nationwide Health Insurance Database (SNIIRAM) linked to emergency departments records within five areas. Rationale and design of SACHA study}

Running head: Emergency departments' bleedings and anti-thrombotic drugs

Jacques BOUGET ${ }^{a, b}$, Frédéric BALUSSON ${ }^{\text {a }}$, Lucie-Marie SCAILTEUXX ${ }^{a, c,{ }^{*}}$, Maxime MAIGNAN ${ }^{d}$, Pierre-Marie ROY ${ }^{e}$, Erwan L'HER ${ }^{f}$, Laure PAVAGEAU ${ }^{g}$, Emmanuel NOWAK $^{\text {h,i }}$

aUniv Rennes, REPERES [Pharmacoepidemiology and Heath Services Research] - EA 7449, F35000 Rennes, France

bUniversity hospital, Emergency Department, F-35033 Rennes, France

'University hospital, Pharmacovigilance, Pharmacoepidemiology and drug information center, F-35033 Rennes, France

dUniversity Hospital, Emergency Department, F-38043 Grenoble, France

eUniversity hospital, Emergency Department, F-49033 Angers, France

fUniversity hospital, Emergency Department, F-29609 Brest, France

'University hospital, Emergency Department, F-44093 Nantes, France

${ }^{\mathrm{h}} \mathrm{CHU}$ de Brest, F-29200, France

'Inserm CIC 1412, IFR 148, Université de Brest, F-29200 Brest, France

*Corresponding author:

luciemarie.scailteux@chu-rennes.fr

EA 7449 REPERES, Campus Santé Villejean, bâtiment 6, rez-de-chaussée, 2 avenue du Prof. Léon Bernard 35043 Rennes, France 


\section{ABSTRACT}

Bleeding represents the most recognised and feared complications of antithrombotic drugs including oral anticoagulants. Previous studies showed inconsistent results on the safety profile. Among explanations, bleeding definition could vary and classification bias exist related to the lack of medical evaluation.

To quantify the risk of major haemorrhagic event and event-free survival associated with antithrombotic drugs (Vitamin K Antagonist [VKA], non-VKA anticoagulant [NOAC], antiplatelet agent, parenteral anticoagulant) in 2012-2015, we linked the French nationwide Health Insurance database (SNIIRAM) with a local "emergency database" (clinical and biological data collected in clinical records). In the VKA-NOAC comparison, a Cox regression analysis will be used to estimate the hazard ratio of major haemorrhagic event adjusted on gender, modified HAS-BLED score and comorbidities. A distinction on the type of major haemorrhagic event (intracranial, gastrointestinal and other haemorrhagic events) was made. We present here the study protocol and the databases linkage results.

Using six linkage keys, among 3,837,557 hospital visits identified in SNIIRAM, 5264 have been matched with a major haemorrhagic event identified in the "emergency database", thus clinically confirmed. The 1090 unmatched haemorrhagic events could be explained by the fact that patients were not extracted in the SNIIRAM database (patients living in accommodation establishment with internal use pharmacy, military people with specific insurance...).

We showed the value of SNIIRAM enrichment with a clinical database, a necessary step to categorise haemorrhagic events by a clinically relevant definition and medical validation; it will allow to estimate more accuracy each type of haemorrhagic event.

Keywords: antithrombotic, population-based study, emergency, linkage, bleeding.

\section{INTRODUCTION}

Antithrombotic drugs, i.e. oral anticoagulants as well as platelet aggregation inhibitors, have demonstrated significant benefits in preventing venous or arterial thrombotic events, especially in coronary disease, stroke, atrial fibrillation (AF), venous thromboembolism (VTE) and mechanical heart valves [1]. These drugs are commonly prescribed and their long-term use is increasing, particularly in elderly. Bleeding represents the most well-known and feared complications of antithrombotic drugs. Numerous studies on adverse events reported anticoagulants as the first drug class implicated in haemorrhage and specifically intracranial haemorrhage (ICH) which often results in substantial morbidity and mortality [2]. Using adverse events from a National Surveillance System database, Budnitz et al. demonstrated that warfarin and oral platelet aggregation inhibitors were respectively the first and the third drug classes leading to emergency department and hospitalization in adults 65 years of age or older [3]. Gastrointestinal bleeding and intracranial haemorrhage are expected as adverse effects of platelet aggregation inhibitors [4-6]. In a historical cohort, we reported that platelet aggregation inhibitors and oral anticoagulants were equally implicated in the incidence of major haemorrhage seen in an emergency department [7]. More recently, except for 
patients with mechanical heart valves, non-VKA oral anticoagulants (NOAC) were licensed for quite the same indications than vitamin $\mathrm{K}$ antagonists (VKA): prevention of stroke and systemic embolism in patients with non-valvular AF, curative and preventive treatment of VTE, thromboembolic prophylaxis before knee or hip replacement. International multicentre trials have shown noninferiority to warfarin in patients with $\mathrm{AF}$ with lower risk of intracranial haemorrhage but a higher risk of gastrointestinal bleeding [8-10]. Several reports from registries and analysis of claims databases [11-48] have recently suggested, compared with VKA, a similar safety profile of NOAC in the community and in randomised trials. However, meta-analyses $[49,50]$ highlighted inconsistency among those observational studies using different designs: Weeda et al. [49] showed a significant higher risk of gastrointestinal bleeding in studies that relied on claims without clinical identification of bleeding events, leading misclassification bias. Moreover, definitions of major bleeding were variable across studies. Differences between cohort and cross-sectional studies [50] such as heterogeneity of patient characteristics and use of propensity score analysis including various confounding factors held to various incidence rates of bleeding. Thus, the magnitude of bleeding risk associated with all these antithrombotic drugs remains unclear in the real-world clinical practice.

Emergency departments represent a privileged place to observe and to report outpatient adverse drugs events [51], in particular bleeding associated with antithrombotic drugs. Amazingly, to our knowledge, no data based on prospective assessment of emergency department records of subjects referred for bleeding has been reported so far. We set up SACHA study (Survey of acute haemorrhage with antithrombotic drugs), a prospective multicentre study with a three-year inclusion (2012-2015) period and a 6-month follow-up.

Using a local "emergency database" linked with the French nationwide Health Insurance database, the primary objective was to quantify the risk of major bleeding associated with antithrombotic drugs; in a relevant comparison such as VKA-NOAC, we will compare the event-free survival. Secondary objectives were to describe the clinical and therapeutic management of these bleeding events and 1-month and 6-month prognosis (vital status, thrombotic events and/or bleeding recurrence). We herein report methods in details, following RECORD checklist [52], with a particular emphasis on efforts addressing sources of bias and linkage process between the nationwide and local databases. 


\section{METHODS}

\section{Study design}

Called the SACHA (survey of acute haemorrhage with antithrombotic drugs) project, we set up a prospective population-based study linking French Health Insurance Database (SNIIRAM) to data from all emergency departments located within five defined areas surrounding large cities (Angers, Brest, Grenoble, Nantes and Rennes) in France. The current study got regulatory approval (CNIL, DR2013-488 with subsequent substantial modification DR-2016-489); ClinicalTrials.gov identifier: NCT02886533.

Funding: This study was supported by the National Clinical Research Hospital Program of the French Ministry of Health (PHRC-12-009-0243).

\section{Data sources and variables}

(i) SNIIRAM links anonymously and comprehensively a health reimbursement database (DCIR) to the French hospital discharge database (PMSI) [53]. DCIR contains basic data such as age, date of death, and data on drug prescription and delivery including all reimbursed deliveries with strength per unit, number of units per pack for each drug as well as the date of prescription and dispensing. PMSI contains diagnostic codes (International Classification of Disease, 10th revision, ICD-10), admission dates and medical acts (Common Classification of Medical Acts [CCMA] classification) for all hospitalizations either in public or private hospitals; PMSI does not contain information as regards drugs used during hospital visit.

(ii) From the emergency department, clinical and biological data collected in clinical records as regards major haemorrhagic events (ICD-10 codes listed in annex 1) related to antithrombotic drugs (see section outcome and exposure) were reported in an "emergency database": demographics (month and year of birth, sex), medical history, co-morbid conditions, drug class, indication and duration of antithrombotic agent, concomitant medical treatment, type of bleeding/outcome, vital signs at admission, contributory procedures that led to diagnostic of major bleeding (CT scan, endoscopy), biological data on admission, therapeutic haemorrhagic event management in the emergency room, time between admission and diagnosis, time between admission and reversal therapy, length of stay in hospital, and decision about antithrombotic treatment after the first major haemorrhagic event. All cases of major haemorrhagic event were clinically confirmed by clinician. 


\section{Source population}

Thanks to SNIIRAM, we included all adult (> 18 year) subjects, living within the five above mentioned areas, affiliated to French Health Insurance System (whatever the insurance plan), with at least one reimbursement for an antithrombotic drug (list in annex 2) in 2012-2015.

Exposure. Using SNIIRAM, we considered all antithrombotic drugs, alone or in combination, between 2012 and 2015, whatever the indication and dosage drug: oral anticoagulants defined by VKA (warfarin, fluindione, acenocoumarol), and NOAC (dabigatran, rivaroxaban, apixaban); antiplatelet agents (aspirin, clopidogrel, ticagrelor, prasugrel...); parenteral anticoagulants (unfractionned heparin (UFH), low molecular weight heparin (LMWH), fondaparinux, heparinoid). For analyses, a "dose" variable was defined as follows using packaging type delivered: low (dabigatran $110 \mathrm{mg}$, rivaroxaban $10 \mathrm{mg}$, apixaban $2.5 \mathrm{mg}$ twice a day; calciparin 2500 or $5000 \mathrm{UI}$, enoxaparin 2000 or $4000 \mathrm{UI}$, nadroparin $2850 \mathrm{UI}$, reviparin $1432 \mathrm{UI}$, tinzaparin2500 or $3500 \mathrm{UI}$, fondaparinux $2.5 \mathrm{mg}$, UFH $5000 \mathrm{UI}$ ), and high (dabigatran $110 \mathrm{mg}$ twice a day or $150 \mathrm{mg}$ twice a day, rivaroxaban 15 or 20 mg, 15 mg twice a day; UFH > 5000 Ul or other dosage for LMWH).

We defined a new user, in each antithrombotic class (annex 2), as a patient who has no reimbursement for that class in his or her medication history.

Primary objectives' outcome. From the patients in the SNIIRAM database, between January 1, 2013 and December 31, 2015 we prospectively and consecutively identified all clinically confirmed case of major haemorrhagic events (annex 1) occurring in patients exposed to antithrombotic drug in the community and which motivated care in an emergency department (see list of participating centres in annex 3). Some events were not considered: major haemorrhagic event in patients during hospitalization whereas patient was referred for another reason to emergency room; patients exposed to an antithrombotic drug living outside of the defined areas; intentional overdose of antithrombotic drugs. No informed and signed consent was needed for the basic survey. In contrast, to obtain the 1-month and 6-month follow-up, each included patient received a non-opposition letter and in case of a declared opposition, no data were collected on follow-up.

All public and private care facilities emergency departments in the defined areas able to receive and take care of patients referred for bleeding event as well as pre-hospital emergency medical services participated in. Patients were firstly identified through haemorrhage at emergency admission: computerised requests based on several related-haemorrhagic diagnostic codes (list in annex 4) and specific emergency therapies (red blood transfusion, platelet transfusion, vitamin $\mathrm{K}$, protamin sulfate, PCC (prothrombin complex concentrate) and FEIBA) were made on electronic health records. 
In each emergency department, the local referent medical doctor validated definitive inclusion of all screened records as regards bleeding severity (primary outcome, see below).

More specifically, major haemorrhagic event was defined by at least one of the following criteria: unstable hemodynamic (systolic arterial pressure $<90 \mathrm{mmHg}$ or mean arterial pressure $<65 \mathrm{~mm} \mathrm{Hg}$ ) or haemorrhagic shock, uncontrollable bleeding, need for transfusions or haemostatic procedure (embolization, endoscopic procedure, surgery), a life-threatening location such as intracranial, intraspinal, intraocular, retroperitoneal, pericardial, thoracic, intra-articular, intramuscular haematoma with compartment syndrome, acute gastrointestinal bleeding. We also considered major haemorrhagic event in case of epistaxis with at least two procedures of nasal packing and in case of haematuria when bleeding remained during more than 12 hours despite bladder washing. We anticipated some differential association according to the type of major haemorrhagic event (see annex 5 for details) and defined 3 groups: intracranial haemorrhage, gastrointestinal bleeding and other bleeding events.

Secondary outcome concerned event-free survival.

Secondary objectives' outcomes. First, we focused on initial therapeutic haemorrhagic events management, especially the use of red blood transfusion, platelet transfusion, vitamin $\mathrm{K}$, protamin sulfate, PCC or FEIBA. Secondly, at 1 month and at 6 months after the first major haemorrhagic event (primary outcome), we identified recurrence of major haemorrhagic event (as previously defined) or occurrence of ischemic event (ischemic stroke, transient ischemic attack, myocardial infarction or acute coronary syndrome, deep vein thrombosis or pulmonary embolism, or any peripheral arterial thrombosis) and vital status. We kept in mind the initial indication of antithrombotic agent and whether this agent was withdrawn or replaced by another one after the first major haemorrhagic events.

Linkage. The following key variables were available in SNIIRAM and "emergency" databases: date of birth (month, year), gender, date (day, month, year) of hospital entry +/- 3 days, type of antithrombotic drug, geographic area of the first antithrombotic drug delivery, care facilities (participating centres). Hits were defined as an emergency department stay identified in the SNIIRAM database which matched on key variables with an event selected in the "emergency database" (see annex 6 for linkage details). Duration stay consistency was also assessed to help choosing the most appropriate hit. Patients included in the "emergency database" who were not linked to the SNIIRAM database have been considered as not belonging to the SNIIRAM extraction. 
For note, modified HAS-BLED scoring and Charlson comorbidity index required SNIIRAM data for a fair assessment in all subjects exposed to an antithrombotic drug whether or not they experienced a major bleeding event for which they were referred to hospital.

Comorbidities. A modified HAS-BLED score derived from Pisters et al. [54] and already used by some authors $[23,24]$ was calculated (see annex 7 ). Of note, SNIIRAM does not include laboratory results, thus we were not able to assess a labile international normalized ratio (INR) initially used in the original HAS-BLED score. In addition, this item does not make sense in new users or even in prevalent users of NOAC. At variance with the original score, items were calculated from data available within a year before antithrombotic first use. At the first antithrombotic reimbursement date, a high and low bleeding risk will be defined by, respectively, a modified HAS-BLED score $>2$ or $\leq 2$; of note the modified HAS-BLED maximal score is 8 points instead of 9 in the original one. All analyses were adjusted on these bleeding risks. We used the modified Charlson comorbidity index (see annex 8) to assess patients' overall comorbidity burden [55]. From the medical history available in the month preceding the first delivery of antithrombotic, we extrapolated the indication for antithrombotic. As regards the anticoagulation indications, we considered three main reasons: deep vein thrombosis or pulmonary embolism (VTE), short-term VTE preventive setting (for instance hip or knee replacement surgery), atrial arrhythmia with or without peripheral embolism (list of codes in annex 9); others were classified as unknown or miscellaneous.

Statistical methods and variables. Statistical analyses will focus on patients newly exposed to oral anticoagulant during the 2013-2015 period, without any reimbursement of oral anticoagulant in 2012, with the first delivery date identified through SNIIRAM database.

Focusing on the VKA - NOAC comparison, we will analyse patients with at least one reimbursement of VKA or NOAC with or without oral antiplatelet agents or parenteral anticoagulant without restriction on the indication of the anticoagulant used; the first type of oral anticoagulant will be used as the exposure category; VKA will be considered as the reference group. We will perform descriptive statistics: they will concern for categorical variables, frequency and percentage, and mean \pm standard deviation or median (inter-quartile range) for continuous variables whether the distribution is normal or not. Description will focus on major haemorrhagic event characteristics and clinical parameters according to antithrombotic drug exposure. The main analysis will follow an ontreatment principle as we deal with a safety outcome. Exposed time will be censored the earliest date of end of the study period, date of major haemorrhagic event, date of death, date of defined area leaving, date of anticoagulant switch (between VKA and NOAC) or, for the main analysis, date of 
NOAC dose change (low to high dose and vice versa). Crude incidence rates for major haemorrhagic event per 10000 person-months will be calculated, within each HAS-BLED strata, and distinguishing duration of use $(<6$ month, 6 to 12 months and $>1$ year, as we anticipate that instantaneous bleeding risk was not constant over time), dose (low or high) and type of major haemorrhagic event (intracranial haemorrhage, gastrointestinal bleeding and other bleeding events). For further comparison within each analysis, Cox proportional hazard regression analysis will be used to estimate the hazard ratio of major haemorrhagic event adjusted on gender, modified HAS-BLED score and comorbidities; a similar analysis will be done for the event-free survival outcome. As a sensitivity analysis, for each indication, we will estimate a propensity score and use stabilized inverse probability of treatment weighting (SIPTW) regression modelling.

Subsequent analyses (descriptive analyses and incidence rates estimation) for the new users of parenteral anticoagulants users group and the new users of the antiplatelet agent users group will follow the same principles.

Study size. Our main analysis and comparison will concern the NOAC and VKA new users: the power calculation took into account NOAC major haemorrhagic events, considering that NOAC were recently commercialized and less prescribed than VKA on the 2012-2015 period; under the assumption that the cumulative percentage of major bleeding at 12 months was $1.5 \%$ in the VKA group (reference group), 120,000 patients overall were needed to detect a relative risk of 1.20 with $90 \%$ power at a two-sided $5 \%$ alpha-level, accounting that VKA dispensation is roughly 4-fold greater (ratio 4:1) than NOAC group. For the parenteral anticoagulant group, no comparison is planned. For antiplatelet agents, a posteriori power calculation is planned.

Data access and cleaning methods. On-site monitoring was performed to specifically check the validity of the primary outcome and eligibility criteria. Queries were edited to minimize errors identified as outliers or missing values.

Bias. We think that major bleeding always led to hospital admission. Being doubtful as regards accuracy of PMSI database (hospital discharge diagnoses) to adequately categorize patients as being referred for major haemorrhagic event, we comprehensively and prospectively collected data from all emergency departments within selected areas. Those areas were defined as catchment region surrounding each main city hospitals in order to avoid missing any major bleeding being cared elsewhere. Medical validation of primary outcome ensured minimization of classification bias; on the other hand, drug exposure was based on SNIIRAM database (reimbursement claims). Most importantly, the main analysis focused on first users, thus avoiding immortal bias. In addition, 
selection bias is minimized as SNIIRAM database is quasi exhaustive within selected areas. Lastly, to consider indication bias, analyses will be stratified on a modified HAS-BLED score [54] with further adjustment on a modified Charlson comorbidity index [55]. Those scores and index are measured through SNIIRAM database in all analysed subjects thus minimising classification bias.

\section{RESULTS}

Between 2013 and 2015, 3,837,557 hospital visits were identified in the SNIIRAM database, and 6,354 events in the "emergency database". Using the different keys, we identified 18,654 hits (see method section for hit definition) in the SNIIRAM database for 6,195 events in the "emergency database". We checked the consistency between the "emergency" and the SNIIRAM databases on two points: i) geographic area considering that patients identified in the SNIIRAM database could come from specific French region but outside of the defined area (see Annex 3); ii) anti-thrombotic drug considering that a potential inconsistency could exist between the drug class exposure at the haemorrhagic event date in the "emergency database" and the SNIIRAM database. Inconsistent hits were then excluded.

Finally, among those 3,837,557 hospital visits, 5264 have been matched with a major haemorrhagic event identified in the "emergency database", thus clinically confirmed (figure 1). More in depth, 4,751 events matched with only one hospital visit in the SNIIRAM database, and 513 events matching with 2, 3 or 4 hospital visits in the SNIIRAM database. For these 513 events, a selection on the most similar date of emergency department entrance and hospital discharge, and on the patient concomitant reimbursed drugs was made to select the right event. The remaining 1090 events found in the "emergency database" are thought to be related to patients out of the SNIIRAM extraction (see discussion section).

As regards the at-risk cohort of subjects exposed to antithrombotic drugs in 2013-2015 living in the defined area, identified through SNIIRAM, 102,560 subjects had been categorised as oral anticoagulant (VKA or NOAC, +/- antiplatelet agents) users.

\section{DISCUSSION}

The originality of our methodology lies on the linkage of Health Insurance Data to data from all emergency departments within a well-defined area. Dealing with the challenge of linking two databases allowed us: firstly, to enrich the SNIIRAM database, an anonymous medico-administrative database, with a clinical database; secondly, to complete specific missing data (date of antithrombotic initiation) in the clinical database thanks to SNIIRAM; thirdly, to have a clinically confirmed diagnosis. Such a methodology has been previously used for another safety issue [56]. 


\section{Strengths and limitations.}

Based on information collected in medical records ("emergency database"), each major haemorrhagic event was categorised by a clinically relevant definition, without restriction to a validated indication, and was medically validated and carefully checked thereafter. Such an approach authorises a more accurate estimate of haemorrhagic risk. A recent study [57] showed that the manual medical records review was a necessary step especially for gastro-intestinal and urogenital bleeds, improving the true estimated incidence rates; in comparison, the codes used alone in database overestimated the incidence rates. Furthermore, such a medical review overcomes the classification bias related to retrospective analysis of data based on hospital discharge diagnosis (ICD-10 codes) without medical validation [49]. We had some suspicion about the accuracy of hospital discharge diagnoses in PMSI database to adequately categorize patients as being referred for major bleeding.

To define bleeding as a major haemorrhagic event, we used criteria of major bleeding recommended by the French National Authority for Health (HAS) [58] rather than criteria of the International Society of Thrombosis and Haemostasis (ISTH) [59]. These criteria were anyway close to each other and we considered that a fall in haemoglobin level of $20 \mathrm{~g} / \mathrm{l}$ or more was a tricky criterion to estimate when recruiting in emergency rooms as the baseline haemoglobin level was not often available. These same criteria were used in other observational studies $[31,32,47]$. Otherwise, considering indication bias when comparing VKA to NOAC, we plan a sensitivity analysis on "common" indications. For note, NOAC have no indication in valvular heart diseases (cardiac prothesis); the VKA - NOAC comparison was thus not realised on this indication and this sub-group analysis was not performed.

Secondly, exhaustiveness of case identification is a main issue: all emergency departments of the defined catchment region surrounding each main city hospitals participated in our study.

Thirdly, to ensure that subjects referred for major haemorrhagic event were truly cases arising from the at-risk cohort (subjects exposed to antithrombotic agents living in the area), careful check of data on residency as well as linkage processing were conducted and monitored. Patients living in the area with a major haemorrhagic event occurring outside of the defined area (for instance, on vacation) were also captured through SNIIRAM but not in the "emergency database"; they are supposed to be marginal; if not, even they had not been clinically confirmed, we plan to include them in a sensitivity analysis to estimate the hazard ratio of major haemorrhagic event. 
Fourthly, drug exposure was assessed through clinical records (collected in emergency rooms or by contact with the general practitioner of the patient in case of missing data in the emergency clinical record) as well as on claim database, the two data sources being linked allowing cross-checking; recent and last drug exposure is anticipated to be reliably assessed through clinical records and we know otherwise that some drug exposure could not be traced by SNIIRAM (prescription and delivery within hospital or retirement homes with a dedicated pharmacy); on the other hand, SNIIRAM was more reliable to reconstruct the history of drug exposure (including initiation, switch, stop) than the patient interview (data supplied in emergency clinical records), especially when patient is exposed since a long time. Recent drug exposure consistency was considered when linking events between SNIIRAM and "emergency database" and SNIIRAM was the reference to classify first use anticoagulant type.

Fifthly and most importantly, the main analysis focused on first antithrombotic users (new users), thus avoiding immortal bias.

Sixthly, to consider indication bias, analyses will be stratified on modified HAS-BLED score and used further adjustment on components of modified Charlson comorbidity index. As regards the ontreatment principle, we planned to censor exposure time at the oral anticoagulant switch.

On the other hand, we acknowledge that there was no centralized event adjudication. All deaths, specifically those occurring outside the hospital will be identified but cause remained unknown.

Last but not least, as regards the 1090 events found in the "emergency database" but not in the SNIIRAM database, some explanations could be considered: a part concerned patients living in accommodation establishment for dependent people with internal use pharmacy (especially since the exposed population is rather old); the drug dispensation in such an establishment is not available in the SNIIRAM database and patients have not been extracted in the source population then. Another explanation concerned patients living in the Brest area which includes an overrepresentation of military people whose specific insurance is not include in the SNIIRAM and who are supposed to be also not extracted in the source population. Finally, as regards patients with parenteral anticoagulant identified through the "emergency database", they are supposed to be hospitalised in care facilities and then not extracted in SNIIRAM database; note that we are not interested in these patients, considering an analysis focused on bleeding from the community. Additionally, we also could not rule out some misclassification as regards antithrombotic drug exposure when clinically assessed. 


\section{Discussion about methodologies used in real-world studies}

Since 2014, several real-world observational studies investigated the bleeding risk of NOAC in many countries [11-48]. Annex 10 reports some characteristics of these post-approval published studies and shows heterogeneity for many aspects: most of them used retrospectively data from nationwide administrative or insurance databases with limited clinical information - no access for patient's mortality [22]. Few studies were prospective $[13,16,19-21,30,34,37,38,47,48]$. Medical validation of patient's bleeding events was scarce $[16,30,34,37,38,47]$. The follow-up of included patients were very different (from 1 month to 2 years). Most studies included only patients with atrial fibrillation $[11-20,23,25-29,31-35,38,40,42-45]$, others only patients with venous thromboembolism diseases $(21,36,37,46)$, few studies focused on a type of haemorrhagic event, gastrointestinal bleeding $[22,24,33,39]$, or intracerebral bleeding $[28,33,37,43]$. The numbers of patients exposed to VKAs and to the different DOACs were very various, from few hundreds to many tens of thousands. The bleeding criteria are also quite different. Some studies included patients with prior warfarin exposure because all pivotal trials and routine clinical practice, the majority of patients initiating NOAC have previously used VKA. In Maura et al. study [23], patients with contraindications to treatment (history of valvular heart disease, ongoing cancer treatment, dialysis for end-stage renal disease, hematologic disease or certain immune system disorders considered to be at higher risk of major bleeding (LTD or ICD-codes D50-D89), hepatic cirrhosis or fibrosis or liver failure, acute bleeding peptic ulcer) were excluded. These different designs led to various and sometimes contradictory results, about incidence of the haemorrhagic risk of the different antithrombotic drugs and especially the anticoagulant agents. For note, study chronology faced to the time of drug approval may influence results in terms of safety: Laliberté et al. [18] reported a higher intracranial bleeding risk with rivaroxaban than other similar studies because of less experience of the prescribers.

With our SACHA current study, using French nationwide database enriched with an "emergency database", we will estimate the risk of clinical confirmed major haemorrhagic event in patients using antithrombotic drugs, regardless the antithrombotic indication, in real-world clinical practice, taking into account comorbidities, co-medications and medical history on a 3-years period. Contrary to the most previous studies where haemorrhagic risk estimation was based on the antithrombotic indication [22,24,41,47], we will consider patients baseline profile using comorbidities and the modified HAS-BLED score and the antithrombotic dose and duration. In our opinion, they appear as more relevant haemorrhagic risk factors, which will provide a better haemorrhagic risk estimation associated with determinate therapeutic classes. 


\section{REFERENCES}

1. Ageno W., Gallus A.S., Wittkowsky A., Crowther M., Hylek E.M., Palareti G. Oral anticoagulant therapy: Antithrombotic Therapy and Prevention of Thrombosis, 9th ed: American College of Chest Physicians Evidence-Based Clinical Practice Guidelines. Chest. (2012) 141(2 Suppl):e44S-e88S.

2. Witt D.M., Delate T., Hylek E.M., Clark N.P., Crowther M.A., Dentali F. et al. Effect of warfarin on intracranial hemorrhage incidence and fatal outcomes. Thromb. Res. (2013)132 770-775.

3. Budnitz D.S., Lovegrove M.C., Shehab N., Richards C.L. Emergency hospitalizations for adverse drug events in older Americans. N. Engl. J. Med. (2011) 365 2002-2012.

4. Baldi G., Altomonte F., Altomonte M., Ghirarduzzi A., Brusasco C., Parodi R.C. et al. Intracranial haemorrhage in patients on antithrombotics: clinical presentation and determinants of outcome in a prospective multicentric study in Italian emergency departments. Cerebrovasc. Dis. (2006) 22 286-293.

5. García Rodríguez L.A., Lin K.J., Hernández-Díaz S., Johansson S. Risk of upper gastrointestinal bleeding with low-dose acetylsalicylic acid alone and in combination with clopidogrel and other medications. Circulation. (2011) 123 1108-1115.

6. Valkhoff V.E., Sturkenboom M.C.J.M., Kuipers E.J. Risk factors for gastrointestinal bleeding associated with low-dose aspirin. Best Pract Res Clin Gastroenterol. (2012) 26 125-140.

7. Bouget J., Oger E., Nicolas N. Emergency admissions for major haemorrhage associated with antithrombotics: a cohort study. Thromb. Res. (2015) 135 84-89.

8. Ruff C.T., Giugliano R.P., Braunwald E., Hoffman E.B., Deenadayalu N., Ezekowitz M.D. et al. Comparison of the efficacy and safety of new oral anticoagulants with warfarin in patients with atrial fibrillation: a meta-analysis of randomised trials. Lancet. (2014) 383 955-962.

9. van Es N., Coppens M., Schulman S., Middeldorp S., Büller H.R. Direct oral anticoagulants compared with vitamin $\mathrm{K}$ antagonists for acute venous thromboembolism: evidence from phase 3 trials. Blood. (2014) 124 1968-1975.

10. van der Hulle T., Kooiman J., den Exter P.L., Dekkers O.M., Klok F.A., Huisman M.V. Effectiveness and safety of novel oral anticoagulants as compared with vitamin $\mathrm{K}$ antagonists in the treatment of acute symptomatic venous thromboembolism: a systematic review and meta-analysis. J. Thromb. Haemost. (2014) 12 320-328.

11. Graham D.J., Reichman M.E., Wernecke M., Zhang R., Southworth M.R., Levenson M. et al. Cardiovascular, bleeding, and mortality risks in elderly Medicare patients treated with dabigatran or warfarin for nonvalvular atrial fibrillation. Circulation (2015) 131 157-164.

12. Lauffenburger J.C., Farley J.F., Gehi A.K., Rhoney D.H., Brookhart M.A., Fang G. Effectiveness and safety of dabigatran and warfarin in real-world US patients with non-valvular atrial fibrillation: a retrospective cohort study. J. Am. Heart Assoc. (2015) 4 pii:e001798. doi: 10.1161/JAHA.115.001798. 
13. Beyer-Westendorf J., Ebertz F., Förster K., Gelbricht V., Michalski F., Köhler C. et al. Effectiveness and safety of dabigatran therapy in daily-care patients with atrial fibrillation. Results from the Dresden NOAC Registry. Thromb. Haemost. (2015) 113 1247-1257.

14. Nishtala P.S., Gnjidic D., Jamieson H.A., Hanger H.C., Kaluarachchi C., Hilmer S.N. 'Real-world' haemorrhagic rates for warfarin and dabigatran using population-level data in New Zealand. Int. J. Cardiol. (2016) 203 746-752.

15. Hernandez I., Baik S.H., Piñera A., Zhang Y. Risk of bleeding with dabigatran in atrial fibrillation. JAMA Intern. Med. (2015) 175 18-24.

16. Yavuz B., Ayturk M., Ozkan S., Ozturk M., Topaloglu C., Aksoy H. et al. A real world data of dabigatran etexilate: multicenter registry of oral anticoagulants in nonvalvular atrial fibrillation. J. Thromb. Thrombolysis. (2016) 42 399-404.

17. Tamayo S., Frank Peacock W., Patel M., Sicignano N., Hopf K.P., Fields L.E. et al. Characterizing major bleeding in patients with nonvalvular atrial fibrillation: a pharmacovigilance study of 27467 patients taking rivaroxaban. Clin. Cardiol. (2015) 38 63-68.

18. Laliberté F., Cloutier M., Nelson W.W., Coleman C.I., Pilon D., Olson W.H. et al. Real-world comparative effectiveness and safety of rivaroxaban and warfarin in nonvalvular atrial fibrillation patients. Curr. Med. Res. Opin. (2014) 30 1317-1325.

19. Hecker J., Marten S., Keller L., Helmert S., Michalski F., Werth S. et al. Effectiveness and safety of rivaroxaban therapy in daily-care patients with atrial fibrillation. Results from the Dresden NOAC Registry. Thromb. Haemost. (2016) 115 939-949.

20. Camm A.J., Amarenco P., Haas S., Hess S., Kirchhof P., Kuhls S. et al. XANTUS: a real-world, prospective, observational study of patients treated with rivaroxaban for stroke prevention in atrial fibrillation. Eur. Heart J. (2016) 37 1145-1153.

21. Ageno W., Mantovani L.G., Haas S., Kreutz R., Monje D., Schneider J. et al. Safety and effectiveness of oral rivaroxaban versus standard anticoagulation for the treatment of symptomatic deep-vein thrombosis (XALIA): an international, prospective, non-interventional study. Lancet Haematol. (2016) 3 :e12-21.

22. Chang H.-Y., Zhou M., Tang W., Alexander G.C., Singh S. Risk of gastrointestinal bleeding associated with oral anticoagulants: population based retrospective cohort study. BMJ. (2015) 350 h1585.

23. Maura G., Blotière P.-O., Bouillon K., Billionnet C., Ricordeau P., Alla F. et al. Comparison of the short-term risk of bleeding and arterial thromboembolic events in nonvalvular atrial fibrillation patients newly treated with dabigatran or rivaroxaban versus vitamin $\mathrm{K}$ antagonists: a French nationwide propensity-matched cohort study. Circulation. (2015) 132 1252-1260.

24. Abraham N.S., Singh S., Alexander G.C., Heien H., Haas L.R., Crown W. et al. Comparative risk of gastrointestinal bleeding with dabigatran, rivaroxaban, and warfarin: population based cohort study. BMJ. (2015) 350 h1857. 
25. Larsen T.B., Skjøth F., Nielsen P.B., Kjældgaard J.N., Lip G.Y.H. Comparative effectiveness and safety of non-vitamin $\mathrm{K}$ antagonist oral anticoagulants and warfarin in patients with atrial fibrillation: propensity weighted nationwide cohort study. BMJ. (2016) 353 i3189.

26. Lip G.Y.H., Keshishian A., Kamble S., Pan X., Mardekian J., Horblyuk R. et al. Real-world comparison of major bleeding risk among non-valvular atrial fibrillation patients initiated on apixaban, dabigatran, rivaroxaban, or warfarin. A propensity score matched analysis. Thromb. Haemost. (2016) 116 975-986.

27. Yao X., Abraham N.S., Sangaralingham L.R., Bellolio M.F., McBane R.D., Shah N.D. et al. Effectiveness and Safety of Dabigatran, Rivaroxaban, and Apixaban Versus Warfarin in Nonvalvular Atrial Fibrillation. J. Am. Heart Assoc. (2016) 5 pii: e003725. doi: 10.1161/JAHA.116.003725 .

28. Staerk L., Fosbø| E.L., Lip G.Y.H., Lamberts M., Bonde A.N., Torp-Pedersen C. et al. Ischaemic and haemorrhagic stroke associated with non-vitamin $\mathrm{K}$ antagonist oral anticoagulants and warfarin use in patients with atrial fibrillation: a nationwide cohort study. Eur. Heart J. (2017) 38 907-915.

29. Chan Y.-H., Kuo C.-T., Yeh Y.-H., Chang S.-H., Wu L.-S., Lee H.-F. et al. Thromboembolic, Bleeding, and Mortality Risks of Rivaroxaban and Dabigatran in Asians With Nonvalvular Atrial Fibrillation. J. Am. Coll. Cardiol. (2016) 68 1389-1401.

30. Becattini C., Franco L., Beyer-Westendorf J., Masotti L., Nitti C., Vanni S. et al. Major bleeding with vitamin K antagonists or direct oral anticoagulants in real-life. Int. J. Cardiol. (2017) $227261-$ 266.

31. Graham D.J., Reichman M.E., Wernecke M., Hsueh Y.-H., Izem R., Southworth M.R. et al. Stroke, Bleeding, and Mortality Risks in Elderly Medicare Beneficiaries Treated With Dabigatran or Rivaroxaban for Nonvalvular Atrial Fibrillation. JAMA Intern. Med. (2016) 176 1662-1671.

32. Halvorsen S., Ghanima W., Fride Tvete I., Hoxmark C., Falck P., Solli O. et al. A nationwide registry study to compare bleeding rates in patients with atrial fibrillation being prescribed oral anticoagulants. Eur. Heart J. Cardiovasc. Pharmacother. (2017) 3 28-36.

33. Lai C.-L., Chen H.-M., Liao M.-T., Lin T.-T., Chan K.A. Comparative Effectiveness and Safety of Dabigatran and Rivaroxaban in Atrial Fibrillation Patients. J. Am. Heart Assoc. (2017) 6 pii: e005362. doi: 10.1161/JAHA.116.005362 .

34. Xu Y., Schulman S., Dowlatshahi D., Holbrook A.M., Simpson C.S., Shepherd L.E. et al. Direct Oral Anticoagulant- or Warfarin-Related Major Bleeding: Characteristics, Reversal Strategies, and Outcomes From a Multicenter Observational Study. Chest. (2017) 152 81-91.

35. Li X.S., Deitelzweig S., Keshishian A., Hamilton M., Horblyuk R., Gupta K. et al. Effectiveness and safety of apixaban versus warfarin in non-valvular atrial fibrillation patients in 'real-world' clinical practice. A propensity-matched analysis of 76,940 patients. Thromb. Haemost. (2017) 117 1072-1082.

36. Sindet-Pedersen C., Langtved Pallisgaard J., Staerk L., Gerds T.A., Fosbø| E.L., Torp-Pedersen C. et al. Comparative safety and effectiveness of rivaroxaban versus VKAs in patients with venous thromboembolism. A Danish nationwide registry-based study. Thromb. Haemost. (2017) $1171182-$ 
1191.

37. Larsen T.B., Skjøth F., Kjældgaard J.N., Lip G.Y.H., Nielsen P.B., Søgaard M. Effectiveness and safety of rivaroxaban and warfarin in patients with unprovoked venous thromboembolism: a propensity-matched nationwide cohort study. Lancet Haematol. (2017) 4 :e237-44.

38. Helmert S., Marten S., Mizera H., Reitter A., Sahin K., Tittl L. et al. Effectiveness and safety of apixaban therapy in daily-care patients with atrial fibrillation: results from the Dresden NOAC Registry. J. Thromb. Thrombolysis. (2017) 44 169-178.

39. Abraham N.S., Noseworthy P.A., Yao X., Sangaralingham L.R., Shah N.D. Gastrointestinal Safety of Direct Oral Anticoagulants: A Large Population-Based Study. Gastroenterology. (2017) 152 1014-1022.e1.

40. Amin A., Keshishian A., Trocio J., Dina O., Le H., Rosenblatt L. et al. Risk of stroke/systemic embolism, major bleeding and associated costs in non-valvular atrial fibrillation patients who initiated apixaban, dabigatran or rivaroxaban compared with warfarin in the United States Medicare population. Curr. Med. Res. Opin. (2017) 33 1595-604.

41. Cangemi D.J., Krill T., Weideman R., Cipher D.J., Spechler S.J., Feagins L.A. A Comparison of the Rate of Gastrointestinal Bleeding in Patients Taking Non-Vitamin K Antagonist Oral Anticoagulants or Warfarin. Am. J. Gastroenterol. (2017) 112 734-739.

42. Kohsaka S., Murata T., Izumi N., Katada J., Wang F., Terayama Y. Bleeding risk of apixaban, dabigatran, and low-dose rivaroxaban compared with warfarin in Japanese patients with nonvalvular atrial fibrillation: a propensity matched analysis of administrative claims data. Curr. Med. Res. Opin. (2017) 33 1955-1963.

43. Cha M.-J., Choi E.-K., Han K.-D., Lee S.-R., Lim W.-H., Oh S. et al. Effectiveness and Safety of Non-Vitamin K Antagonist Oral Anticoagulants in Asian Patients With Atrial Fibrillation. Stroke. (2017) 48 3040-3048.

44. Denas G., Gennaro N., Ferroni E., Fedeli U., Saugo M., Zoppellaro G. et al. Effectiveness and safety of oral anticoagulation with non-vitamin $\mathrm{K}$ antagonists compared to well-managed vitamin $\mathrm{K}$ antagonists in naïve patients with non-valvular atrial fibrillation: Propensity score matched cohort study. Int. J. Cardiol. (2017) 249 198-203.

45. Hohnloser S.H., Basic E., Nabauer M. Comparative risk of major bleeding with new oral anticoagulants (NOACs) and phenprocoumon in patients with atrial fibrillation: a post-marketing surveillance study. Clin. Res. Cardiol. (2017) 106 618-628.

46. Coleman C.I., Bunz T.J., Turpie A.G.G. Effectiveness and safety of rivaroxaban versus warfarin for treatment and prevention of recurrence of venous thromboembolism. Thromb. Haemost. (2017) 117 1841-1847.

47. Green L., Tan J., Morris J.K., Alikhan R., Curry N., Everington T. et al. A three-year prospective study of the presentation and clinical outcomes of major bleeding episodes associated with oral anticoagulant use in the UK (ORANGE study). Haematologica. (2018) 103 738-745. 
48. Vinogradova Y., Coupland C., Hill T., Hippisley-Cox J. Risks and benefits of direct oral anticoagulants versus warfarin in a real world setting: cohort study in primary care. BMJ. (2018) 362 k2505.

49. Weeda E.R., White C.M., Peacock W.F., Coleman C.I. Rates of major bleeding with rivaroxaban in real-world studies of nonvalvular atrial fibrillation patients: a meta-analysis. Curr. Med. Res. Opin. (2016) 32 1117-1120.

50. He Y., Wong I.C.K., Li X., Anand S., Leung W.K., Siu C.W. et al. The association between nonvitamin $\mathrm{K}$ antagonist oral anticoagulants and gastrointestinal bleeding: a meta-analysis of observational studies. Br. J. Clin. Pharmacol. (2016) 82 285-300.

51. Budnitz D.S., Pollock D.A., Weidenbach K.N., Mendelsohn A.B., Schroeder T.J., Annest J.L. National surveillance of emergency department visits for outpatient adverse drug events. JAMA. (2006) 296 1858-1866.

52. Benchimol E.I., Smeeth L., Guttmann A., Harron K., Moher D., Petersen I. et al. The REporting of studies Conducted using Observational Routinely-collected health Data (RECORD) statement. PLoS Med. (2015) 12 e1001885.

53. Tuppin P., Rudant J., Constantinou P., Gastaldi-Ménager C., Rachas A., de Roquefeuil L. et al. Value of a national administrative database to guide public decisions: From the système national d'information interrégimes de l'Assurance Maladie (SNIIRAM) to the système national des données de santé (SNDS) in France. Rev. Epidemiol. Sante Publique. (2017) 65 (Suppl 4) S149-167.

54. Pisters R., Lane D.A., Nieuwlaat R., de Vos C.B., Crijns H.J.G.M., Lip G.Y.H. A novel userfriendly score (HAS-BLED) to assess 1-year risk of major bleeding in patients with atrial fibrillation: the Euro Heart Survey. Chest. (2010) 138 1093-100.

55. Bannay A., Chaignot C., Blotière P.-O., Basson M., Weill A., Ricordeau P. et al. The Best Use of the Charlson Comorbidity Index With Electronic Health Care Database to Predict Mortality. Med. Care. (2016) 54 188-194.

56. Scailteux L.-M., Balusson F., Vincendeau S., Rioux-Leclercq N., Nowak E. Rationale and design of the CANARI study: a case-control study investigating the association between prostate cancer and 5-alpha-reductase inhibitors for symptomatic benign prostate hypertrophy by linking SNIIRAM and pathology laboratories in a specific region in France. Fundam. Clin. Pharmacol. (2018) 32 120-129.

57. Ruigómez A., Brobert G., Suzart-Woischnik K., García-Rodríguez L.A. Ascertainment and validation of major bleeding events in a primary care database. Pharmacoepidemiol. Drug Saf. (2018) doi: 10.1002/pds.4580. [Epub ahead of print]

58. Pernod G., Godiér A., Gozalo C., Tremey B., Sié P., French National Authority for Health. French clinical practice guidelines on the management of patients on vitamin $\mathrm{K}$ antagonists in at-risk situations (overdose, risk of bleeding, and active bleeding). Thromb. Res. (2010) 126 e167-174.

59. Schulman S., Kearon C., Subcommittee on Control of Anticoagulation of the Scientific and Standardization Committee of the International Society on Thrombosis and Haemostasis. Definition of major bleeding in clinical investigations of antihemostatic medicinal products in non-surgical 
patients. J. Thromb. Haemost. (2005) 3 692-694.

\section{ANNEXES}

Annex 1. ICD-10 codes used in SNIIRAM to detect bleeding events

Annex 2. ATC codes for antithrombotic agents

Annex 3. Participating emergency departments and pre-hospital emergency medical services

Annex 4. Computerised requests made on electronic health records in every participating centre

Annex 5. Different types of major bleeding events

Annex 6. Linkage details

Annex 7. Modified HAS-BLED score

Annex 8. Modified Charlson comorbidity index

Annex 9. Definition of presumed indication of oral anticoagulant, co-morbidities (according to International Classification of Diseases, 10th revision (ICD-10) or medical act classification) and comedications (Anatomical Therapeutic Chemical (ATC) system)

Annex 10. Characteristics of recent real-world observational studies on the bleeding risk of direct oral anticoagulants (meta-analyses excluded)

\section{Annex 1. ICD-10 codes used in SNIIRAM to detect bleeding events}

Diseases of the blood and blood-forming organs and certain disorders involving the immune mechanism

D62 Acute post-haemorrhagic anaemia

D683 Haemorrhagic disorder due to circulating anticoagulants

Diseases of the eye and adnexa

H11.3 Conjunctival haemorrhage

H35.6 Retinal haemorrhage

H43.1 Vitreous haemorrhage

H45.0 Vitreous haemorrhage in diseases classified elsewhere

Diseases of the ear and mastoid process

H92.2 Otorrhagia

Diseases of the circulatory system

131.2 Haemopericardium

160.x Subarachnoid haemorrhage

161.x Intra-cerebral haemorrhage

162.0 Subdural haemorrhage (acute) (non traumatic)

162.1 Non-traumatic extradural haemorrhage

I62.9 Intracranial haemorrhage (non-traumatic), unspecified 
164 Stroke, not specified as haemorrhage or infarction

177.2 Rupture of artery

$185.0 \quad$ Oesophageal varices with bleeding

198.3 Oesophageal varices with bleeding in diseases classified elsewhere

Diseases of the respiratory system

J94.2 Haemothorax

Diseases of the digestive system

K22.6 Gastro-oesophageal laceration-haemorrhage syndrome

K25 Gastric ulcer

K26 Duodenal ulcer

K27 Peptic ulcer, site unspecified

K280

subdivisions for use with categories K25-K28:

.0 Acute with haemorrhage

.2 Acute with both haemorrhage and perforation

$.4 \quad$ Chronic or unspecified with haemorrhage

.6 Chronic or unspecified with both haemorrhage and perforation

K29.0 Acute haemorrhagic gastritis

K51.8 Other ulcerative colitis

K51.9 Ulcerative colitis, unspecified

K62.5 Haemorrhage of anus and rectum

K66.1 Haemoperitoneum

K92.0 Haematemesis

K92.1 Melaena

K92.2 Gastrointestinal haemorrhage, unspecified

Diseases of the musculoskeletal system and connective tissue

M25.0 Haemarthrosis

Diseases of the genitourinary system

N02 Recurrent and persistent haematuria

N92 Excessive, frequent and irregular menstruation

N93.8 Other specified abnormal uterine and vaginal bleeding

N93.9 Abnormal uterine and vaginal bleeding, unspecified

N95.0 Postmenopausal bleeding

Symptoms, signs and abnormal clinical and laboratory finding

R04.0 Epistaxis

R04.1 Haemorrhage from throat

R04.2 Haemoptysis

R04.8 Haemorrhage from other sites in respiratory passages

R04.9 Haemorrhage from respiratory passages, unspecified

R31 Unspecified haematuria

R58 Haemorrhage, not elsewhere classified

Injury, poisoning and certain other consequences of external causes

S00.8 Superficial injury of other parts of head

S01.0 Open wound of scalp

S06.0 Concussion

S06.2 Diffuse brain injury

S06.3 Focal brain injury

S06.4 Epidural haemorrhage

S06.5 Traumatic subdural haemorrhage

S06.6 Traumatic subarachnoid haemorrhage

S27.1 Traumatic haemothorax 
S27.2 Traumatic haemopneumothorax

S36.0 Injury of spleen

S51.7 Multiple open wounds of forearm

S81.8 Open wound of other parts of lower leg

S81.9 Open wound of lower leg, part unspecified

Factors influencing health status and contact with health services

Z51.3 Blood transfusion (without reported diagnosis)

Annex 2. ATC codes for antithrombotic agents

\begin{tabular}{|c|c|c|}
\hline ATC-7 codes & INN & Antithrombotic class \\
\hline B01AA02 & PHENINDIONE & VKA \\
\hline B01AA03 & WARFARINE & VKA \\
\hline B01AA07 & ACENOCOUMAROL & VKA \\
\hline B01AA12 & FLUINDIONE & VKA \\
\hline B01AC04 & CLOPIDOGREL & Antiplatelet inhibitor \\
\hline B01AC05 & TICLOPIDINE & Antiplatelet inhibitor \\
\hline B01AC06 & ACETYLSALICYLIQUE ACIDE & Antiplatelet inhibitor \\
\hline B01AC07 & DIPYRIDAMOLE & Antiplatelet inhibitor \\
\hline B01AC22 & PRASUGREL & Antiplatelet inhibitor \\
\hline B01AC22 & PRASUGREL & Antiplatelet inhibitor \\
\hline B01AC24 & TICAGRELOR & Antiplatelet inhibitor \\
\hline B01AC30 & $\begin{array}{l}\text { DIPYRIDAMOLE \& ACIDE } \\
\text { ACETYLSALICYLIQUE }\end{array}$ & Antiplatelet inhibitor \\
\hline B01АС30 & $\begin{array}{l}\text { CLOPIDOGREL \& ACIDE } \\
\text { ACETYLSALICYLIQUE }\end{array}$ & Antiplatelet inhibitor \\
\hline C10BX02 & $\begin{array}{l}\text { PRAVASTATINE \& ACIDE } \\
\text { ACETYLSALICYLIQUE }\end{array}$ & NOAC \\
\hline B01AE07 & DABIGATRAN & NOAC \\
\hline B01AF01 & RIVAROXABAN & NOAC \\
\hline B01AF02 & APIXABAN & parenteral anticoagulant \\
\hline B01AB01 & HEPARINE & parenteral anticoagulant \\
\hline B01AB04 & DALTEPARINE & parenteral anticoagulant \\
\hline B01AB05 & ENOXAPARINE & parenteral anticoagulant \\
\hline B01AB06 & NADROPARINE & parenteral anticoagulant \\
\hline B01АВ08 & REVIPARINE & parenteral anticoagulant \\
\hline B01AB10 & TINZAPARINE & parenteral anticoagulant \\
\hline B01AX05 & FONDAPARINUX & parenteral anticoagulant \\
\hline
\end{tabular}




\section{Annex 3. Participating emergency departments and pre-hospital emergency medical services}

Area 1. Clinique de l'Anjou, Angers, France, 49000; CHU d'Angers, Angers, France, 49033

Area 2. Hôpital Inter-Armées, Brest, France, 29 240; CHU de Brest, Brest, France, 29609

Area 3. Hôpital Privé Sévigné, Cesson Sévigné, France, 35576; Centre Hospitalier Privé, Saint

Grégoire, France, 35768; CHU de Rennes, Rennes, France, 35033

Area 4. Clinique des Cèdres, Echirolles, France, 38432; Groupe Hospitalier Mutualiste, Grenoble, France, 38028; CHU de Grenoble, Grenoble, France, 38043

Area 5. Nouvelles Cliniques Nantaises, Nantes, France, 44277; CHU de Nantes, Nantes, France, 44093

Annex 4. Computerised requests made on electronic health records in every participating centre

D50.9: iron deficiency anaemia, unspecified

D51.9: vitamin B12 deficiency anaemia, unspecified

D52.9: folate deficiency anaemia, unspecified

D62: acute post-haemorrhagic anaemia

D64.6: anaemia, unspecified

131.2: haemopericardium

160: subarachnoid haemorrhage

161: intracerebral haemorrhage

162: other non-traumatic intracranial haemorrhage

198.2: oesophageal varices with bleeding

J94.2: haemothorax

K22.6: gastro-oesophageal laceration-haemorrhage syndrome

K25.0: gastric ulcer

K26.0: duodenal ulcer

K62.5: haemorrhage of anus and rectum

K66.1: haemoperitoneum

K92.0: haematemesis

K92.1: meloena

K92.2 gastrointestinal haemorrhage, unspecified

M25.0: haemarthrosis

N93.9: abnormal uterine and vaginal bleeding, unspecified

R04.0: epistaxis

R04.1: haemorrhage from throat

R04.2: haemoptysis

R31: unspecified haematuria

R57.1: hypovolaemic shock

R58: haemorrhage, not elsewhere classified

S01.0: open wound of scalp

S06.0: concussion

S06.2: diffuse brain injury 
S06.3: focal brain injury

S06.4: epidural haemorrhage

S06.5: traumatic subdural haemorrhage

S06.6: traumatic subarachnoid haemorrhage

S27.1: traumatic haemothorax

S27.8: injury of other specified intrathoracic organs, haemomediastinum

S36.0: injury of spleen

S39.0: injury of muscle and tendon of abdomen, lower back and pelvis

T06.5: injury of intrathoracic organs with intraabdominal and pelvic organs

T45.5: poisoning: anticoagulants

T79.2: traumatic secondary and recurrent haemorrhage

T79.6: traumatic ischaemia of muscle

Y44.2: agents primarily affecting blood constituents: anticoagulants

Y44.4: agents primarily affecting blood constituents: antithrombotic drugs

\section{Annex 5. Different types of major bleeding events}

1. Intracranial bleeding: subdural haematoma, lobar (or intraparenchymal) haematoma, intraventricular haemorrhage, cerebellar haemorrhage, subarachnoid haemorrhage;

2. Gastrointestinal (GI) bleeding: upper GI tract (oesophagal, gastric, duodenal haemorrhage), lower GI tract (colonic, rectal haemorrhage), haematemesis, meloena;

3. Other bleeding events: muscular haematoma with details about location: lower limb, upper limb, face, thoracic or abdominal haematoma, intramuscular bleeding with compartment syndrome; subcutaneous haematoma with details about location; Haematuria; Haemarthrosis; Haemoptysis; Uterine and vaginal haemorrhage; Epistaxis, dental haemorrhage; Hemoperitoneum, haemopericardium, haemothorax; Scalp injury; Vascular injury.

\section{Annex 6. Linkage details}

In order to link the "emergency database" with the national healthcare database, two different sources were used in SNIIRAM (in DCIR and PMSI):

(1) hospital visit with/out an administrative code for emergency room visit (codification error could have been done or some specific pathway care could exist, i.e., for patients coming from accommodation establishment for dependant people or rehabilitation service);

(2) short visit in emergency room, identified through a package for emergency reception and treatment ("ATU” code [forfait Accueil et Traitement des Urgences]). 
Annex 7. Modified HAS-BLED score

\begin{tabular}{|c|c|c|c|c|c|c|c|c|}
\hline Letter & Original item & $\begin{array}{l}\text { Modified } \\
\text { item }\end{array}$ & New definition & ICD-10 code & $\begin{array}{c}\text { Medical } \\
\text { procedure }\end{array}$ & LTD & ATC & Score \\
\hline $\mathrm{H}$ & $\begin{array}{l}\text { Hypertension } \\
\text { uncontrolled }\end{array}$ & Yes & $\begin{array}{l}\text { Hospitalisation, LTD } \\
\text { affiliation or } \\
\text { treatment* }\end{array}$ & $110,111, \mid 15$ & & 12 & $\begin{array}{l}\mathrm{CO2}, \mathrm{CO3} \\
\mathrm{C07-C09}\end{array}$ & 1 \\
\hline A & $\begin{array}{l}\text { Impaired renal and/or } \\
\text { hepatic function }\end{array}$ & Yes & $\begin{array}{l}\text { Hospitalisation, LTD } \\
\text { affiliation }\end{array}$ & $\begin{array}{l}\text { K70x, K713-5, K717, K721, K73, K74, Z49x, Z99x, I120, I131, N032, } \\
\text { N033, N034, N035, N036, N037, N052, N053, N054, N055, N056, N057, } \\
\text { N17x, N18x, N19, N250, Z490, Z492, Z940, Z992 }\end{array}$ & JVJx & 6,19 & & 1 or 2 \\
\hline$S$ & $\begin{array}{l}\text { Previous history of } \\
\text { stroke }\end{array}$ & No & & G45x, 163x, 1693 & & & & 1 \\
\hline$B$ & $\begin{array}{l}\text { Previous history of } \\
\text { bleeding }\end{array}$ & No & & $\begin{array}{l}\text { I312, I60-I62, I982, J942, K226, K252, K262, K270, K272, K280, K282, } \\
\text { K290, K625, K661, K920-K922, M250, N939, R040-R043, R31, R58, } \\
\text { S064-S066 }\end{array}$ & & & & 1 \\
\hline $\mathrm{L}$ & Labile INR & Not used $^{\S}$ & & & & & & 1 \\
\hline$E$ & Age $>65$ years (Elderly) & No & & & & & & NA \\
\hline D & $\begin{array}{l}\text { Drugsf/alcohol } \\
\text { concomitantly }\end{array}$ & Yes & $\begin{array}{l}\text { Hospitalisation related } \\
\text { to alcohol abuse }\end{array}$ & $\begin{array}{l}\text { E244x, F10x, G312x, G621x, G721x, 1426x, K292x, K70x,K852x, K860x, } \\
\text { O354x, R780x, Y90x, Z714x, Z721x,Z502x }\end{array}$ & & & $\begin{array}{l}\text { B01AC, } \\
M 01 A^{f}\end{array}$ & 1 or 2 \\
\hline
\end{tabular}

The different criteria were assessed in the 12 months preceding inclusion date, i.e., the first observed antithrombotic delivery, except for AAP and NSAID where the criteria were assessed between the first observed antithrombotic delivery and censure date.

Labile INR initially used in the original HAS-BLED score was not considered; this item does not make sense in new users or even in prevalent users of NOAC The modified HAS-BLED score varies from 0 to 8 .

Original items are those described by Pisters et al, Chest 2010; LTD denotes long-term disease;

* at least two deliveries in 2012 of a drug belonging to one of the following ATC classes: C02, C03, C07-C09;

$\S$ of note, this item is not relevant to new users of NOAC;

${ }^{\mathrm{f}}$ antiplatelet agents (B01AC04-B01AC07, B01AC22-B01AC24, B01AC30 or B01AC56) or nonsteroidal anti-inflammatory drugs (M01A, including M01AX02 (niflumic acid) and M01AX17 (nimesulide) but none of the other drugs labelled M01AX; at least one delivery concomitant with any anticoagulant 
Other comorbidities not included in modified HAS-BLED score (assessed in 12 months preceding inclusion date unless otherwise stated):

- History of hemorrhagic stroke (ICD-10 code I63, 164),

- Coronary heart disease (ICD-10 code I20-I25 (hospitalisation or long-term disease registration) or DDAF001, DDAF003 to DDAF010, DDMA003 to DDMA009, DDMA011, DDMA012, DDMA013, DDMA015 to DDMA038, DDQH006, DDQH009-DDQH015, DDAA002, DDFF001, DDFF002, DDPF002),

- Diabetes mellitus (ICD-10 code E10* or E11* for hospitalisation or long-term disease registration; delivery of specific drugs, ATC code A10A or A10B),

- Lipid-lowering drug use (ATC code C10AA*, C10AB*, C10AX* or C10B*),

- Obesity (ICD-10 code E66*),

- antiulcer agent (ATC code A2B),

Diseases of the blood and disorders involving the immune system (ICD-10 code D50-D89, hospitalisation or long-term disease registration). 
Annex 8. Modified Charlson comorbidity index [55]

\begin{tabular}{|c|c|c|c|c|}
\hline Factors & Weight & ICD-10 code & Medical act code & ATC code \\
\hline Congestive heart failure & 2 & $1110, \mid 130,1132,150 x$ & & \\
\hline Peripheral vascular disease & 1 & $\begin{array}{l}\text { I70x, I71x, I731, I738, I739, I771, I790, I792, } \\
\text { K551, K558, K559, Z958, Z959 }\end{array}$ & $\begin{array}{l}\text { EEAFx, ECPFx, ECFAx, EBFAx, EENFx, EEPFx, EEFAx, EECAx, ENNFx, ENFAx, DGAFx, } \\
\text { EDAFx, DGFPx, EDPFx, DGFAx, EDFAx, DGCAx, EDCAx, EDPFx, EDJFx, EDKAx, EDEAx, } \\
\text { EDLFx, EDNFx, EDPFx, EDJFx, EDMAx, EANF002, ECNF002, ECJF001, ECCA007, } \\
\text { ECCA009, ECCA003, ECCA002, ECMA001, ECKA002, EBNF001, EDEA001, EDLF007, } \\
\text { EEJF001, EDCA005, ENAF001, ENAF002, DGKA004,EDNF003, EDKA002 }\end{array}$ & \\
\hline Cerebrovascular disease & 1 & G45x, G46x, H340, 160x-169x & & \\
\hline Dementia & 2 & F00x-F03x, F051, G30x, G311 & & $\begin{array}{l}\text { N06D (at least } 3 \\
\text { deliveries) }\end{array}$ \\
\hline Chronic pulmonary disease & 1 & $\begin{array}{l}\text { I278, I279, J40x-J47x, J60x-J67x, J684, J701, } \\
J 703\end{array}$ & & $\begin{array}{l}\text { R03 (at least } 2 \\
\text { deliveries) }\end{array}$ \\
\hline Mild liver disease & 2 & $\begin{array}{l}\text { B18x, K700-K703, K709, K713-K715, K717, } \\
\text { K73x, K74x, K760, K762-K764, K768, K769, } \\
\text { Z944 }\end{array}$ & & \\
\hline $\begin{array}{l}\text { Moderate or severe liver } \\
\text { disease }\end{array}$ & 2 & $\begin{array}{l}\text { I850, 1859, 1864, 1982, K704, K711, K721, K729, } \\
\text { K765, K766, K767 }\end{array}$ & & \\
\hline Hemiplegia & 1 & $\begin{array}{l}\text { G041, G114, G801, G802, G81x, G82x, G830- } \\
\text { G834, G839 }\end{array}$ & & \\
\hline $\begin{array}{l}\text { Moderate or severe renal } \\
\text { disease }\end{array}$ & 2 & $\begin{array}{l}\text { I120, I131, N032-N037, N052-N057, N18x, } \\
\text { N19x, N250, Z490-Z492, Z940, Z992 }\end{array}$ & & \\
\hline $\begin{array}{l}\text { Any malignancy, including } \\
\text { leukemia and lymphoma }\end{array}$ & 3 & $\begin{array}{l}\text { C00x-C26x, C30x-C34x, C37x-C41x, C43x, } \\
\text { C45x-C58x, C60x-C76x, C81x-C85x, C88x, } \\
\text { C90x-C97x }\end{array}$ & & \\
\hline Metastatic solid tumour & 11 & $C 77 x-C 80 x$ & & \\
\hline AIDS/HIV & 1 & B20x-B22x, B24x, Z21 & & \\
\hline
\end{tabular}

Assessed in 12 months preceding inclusion date (first observed antithrombotic delivery or January 1st 2013 for prevalent users). 
Other comorbidities not included in modified Charlson comorbidity index (assessed in 12 months preceding inclusion date unless otherwise stated):

- History of haemorrhagic stroke (ICD-10 code 163, 164),

- Coronary heart disease (ICD-10 code 120-I25 (hospitalisation or long-term disease registration) or DDAF001, DDAF003 to DDAF010, DDMA003 to DDMA009, DDMA011, DDMA012, DDMA013, DDMA015 to DDMA038, DDQH006, DDQH009-DDQH015, DDAA002, DDFF001, DDFF002, DDPF002),

- Diabetes mellitus (ICD-10 code E10* or E11* for hospitalisation or long-term disease registration; delivery of specific drugs, ATC code A10A or A10B),

- Lipid-lowering drug use (ATC code C10AA*, C10AB*, C10AX* or C10B*),

- Obesity (ICD-10 code E66*),

- antiulcer agent (ATC code A2B),

- Diseases of the blood and disorders involving the immune system (ICD-10 code D50-D89, hospitalisation or long-term disease registration).

Annex 9. Definition of presumed indication of oral anticoagulant, co-morbidities (according to International Classification of Diseases, 10th revision (ICD-10) or medical act classification) and comedications (Anatomical Therapeutic Chemical (ATC) system).

\begin{tabular}{|c|c|c|c|}
\hline Conditions & ICD-10 code & Medical act code & ATC code \\
\hline $\begin{array}{l}\text { AF, peripheral } \\
\text { embolism, ischemic } \\
\text { stroke }\end{array}$ & $\begin{array}{l}\text { I490x, R002x, I470x, I48x, } \\
\text { I481x, I482x, I480x, I489x, } \\
\text { I500x, I501x, I743x, I471x } \\
\text {,I495x, I509x, I742x, I110x, } \\
\text { I498x, K550x, I499x, I479x, } \\
\text { I745x, R000x, I744x, E059x, } \\
\text { I740x, E058x, I748x, K551x, } \\
\text { I132x, E055x, I130x, I741x, } \\
\text { R008x, R4700x, I63x, G45x, } \\
\text { I670x, 164x, I652x, I651x, } \\
\text { I653x, 1658x, I694x }\end{array}$ & 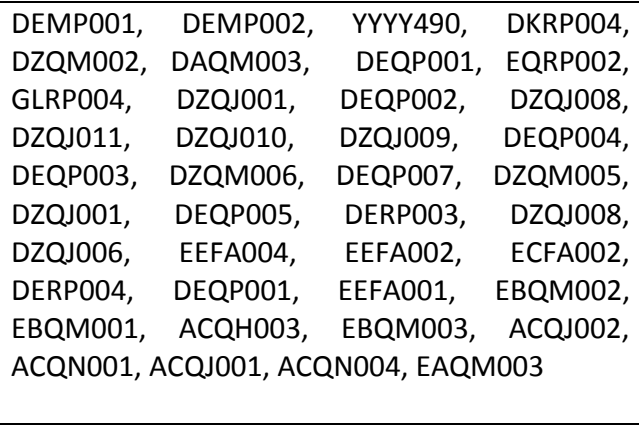 & \\
\hline $\begin{array}{l}\text { Venous } \\
\text { thromboembolism }\end{array}$ & $\begin{array}{l}126 x, 1801 x, 1802 x, 1803 x, \\
\text { I808x, I809x, I81x, I822x, } \\
\text { I823x, I829x, I636x, 1676x, } \\
\text { I828x, G08x, 1800x, I820x, } \\
\text { O871x, I821x, K751x, } \\
\text { O223x }\end{array}$ & $\begin{array}{llll}\text { DHQH003, } & \text { DHQM002, ECQH010, } & \text { ECQH011, } \\
\text { EFQM001, EJQH003, EJQM003, } & \text { EJQM004, } \\
\text { EJQM004, EJQP001, EMQH001, } & \text { EQBPO01, } \\
\text { GFQL002, GFQL006, ZBQH001 } & \end{array}$ & \\
\hline $\begin{array}{l}\text { Lower limb orthopaedic } \\
\text { surgery }\end{array}$ & T840x,Y831x, Z470x, Z966x & 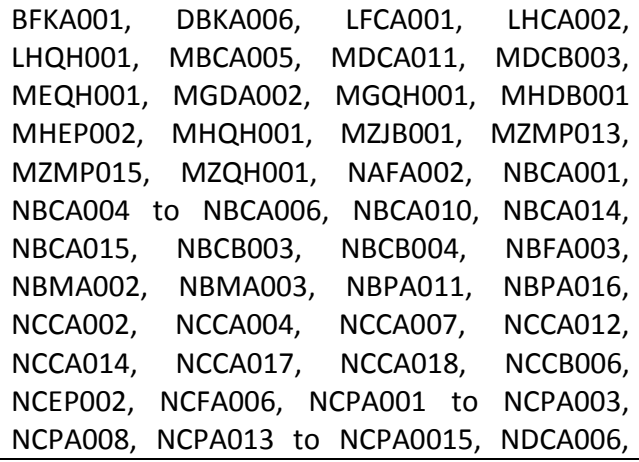 & \\
\hline
\end{tabular}




\begin{tabular}{|c|c|c|c|}
\hline & & $\begin{array}{l}\text { NDEP001, NDFA002, NDGA003, NDPA002 to } \\
\text { NDPA004, NDPA011, NDPA013, NDPA014, } \\
\text { NEEP002, NEFA004, NEFC001, NEJA001, } \\
\text { NEKA001 to NEKA0021, NELA003, NEMA018, } \\
\text { NEMA020, NEMA021, NFCA002, NFCA003, } \\
\text { NFCC002, NFEA002, NFEC002, NFFA002, } \\
\text { NFFA004, NFFC001 to NFFC004, NFJA001, } \\
\text { NFJA002, NFJC002, NFKA001, NFKA002, } \\
\text { NFKA004 to NFKA009, NFMA002, NFMA004, } \\
\text { NFMC002, NFMC003, NFMP001, NFMP002, } \\
\text { NFPA002, NFPC001, NFQC001, NFQH001 } \\
\text { NFQP001, NFRPO01, NGCA001, NGDA002, } \\
\text { NGDA004, NGJA001, NGMP001, NGMP002, } \\
\text { NGQH001, NHDA003 to NHDA005, NHFA001, } \\
\text { NHMA002, NHMA008, NJCA001, NJEA002, } \\
\text { NJEA003, NJFA005, NJMA002, NJMA004, } \\
\text { NJPA018, NJPA025, NJPA029, NZJB001, } \\
\text { NZMP003, NZMP006, NZMP008, NZMP014, } \\
\text { NZQH002, PAGA009 to PAGA011, PAGB004, } \\
\text { PAPA003, ZEMP006, }\end{array}$ & \\
\hline Valvular heart disease & $\begin{array}{l}105 x, 1080 x, 1081 x, 1083 x, \\
1342 x, 2952 x, 2953 x, 2954 x \\
1350 x, 1340 x, 1351 x, 1352 x, \\
1330 x, 1361 x, 1060 x, 1341 x \text {, } \\
Q 231 x, 1062 x, 1348 x, \\
1371 x ', 1339 x, 138 x, 1398 x, \\
1088 x, 1089 x ', 1349 x, 1358 x \text {, } \\
1391 x, \text { Q224x, Q230x }\end{array}$ & $\begin{array}{l}\text { YYYY108, YYYY118, DBMA011, DGKA025, } \\
\text { DGKA011, DBKA011, DBQM001, DBKA006, } \\
\text { YYYY062, DBMA002, DBMA003, DZQJ002, } \\
\text { DBLF001, DBKA011, DBKA009 }\end{array}$ & \\
\hline Diabetes & $\begin{array}{l}\text { E10x, E11x, E12x, E13x, } \\
\text { E14x }\end{array}$ & $\begin{array}{l}\text { BGNA001, BGNP001, BGNP004, BGNP006, } \\
\text { BGNP007, BGNP008 }\end{array}$ & $\mathrm{A} 10 \mathrm{~A}, \mathrm{~A} 10 \mathrm{~B}$ \\
\hline Ischemic heart disease & 120 to 125 & $\begin{array}{l}\text { DDAF001, DDAF003 to DDAF010, DDMA003 to } \\
\text { DDMA009, DDMA011, DDMA012, DDMA013, } \\
\text { DDMA015 to DDMA038, DDQH006, DDQH009 } \\
\text { to DDQH015, DDAA002, DDFF001, DDFF002, } \\
\text { DDPF002 }\end{array}$ & \\
\hline $\begin{array}{l}\text { Hematologic or immune } \\
\text { diseases }\end{array}$ & D50 to D89 & & \\
\hline Lipid-lowering drug & & & $\begin{array}{l}\text { C10AA, } \\
\text { C10AB, } \\
\text { C10AC01, } \\
\text { C10AC02, } \\
\text { C10BA02, } \\
\text { C10BA05, } \\
\text { C10AX, } \\
\text { C10BX03 }\end{array}$ \\
\hline Antiulcer agent & & & $\mathrm{A} 2 \mathrm{~B}$ \\
\hline Anti-platelet inhibitors & & & B01AC \\
\hline
\end{tabular}


Annex 10. Characteristics of recent real-world observational studies on the bleeding risk of direct oral anticoagulants (meta-analyses excluded)

\begin{tabular}{|c|c|c|c|c|c|c|c|}
\hline $\begin{array}{c}\text { Study author } \\
\text { (year) }^{\text {ref }}\end{array}$ & Country & Design & Drugs (N) & Setting & Bleeding definition & Follow-up & Comments \\
\hline $\begin{array}{l}\text { Graham } \\
(2015)^{11}\end{array}$ & $\begin{array}{c}\text { US } \\
\text { Medicare }>65\end{array}$ & $\begin{array}{c}\text { Rs } \\
\text { (claims) }\end{array}$ & $\begin{array}{l}D(67207) \\
W(67207)\end{array}$ & $\mathrm{AF}$ & $\begin{array}{c}\text { ISTH } \\
\text { Code hospitalisation }\end{array}$ & $\begin{array}{l}18205 \text { py } \\
19382 \text { py }\end{array}$ & New users \\
\hline $\begin{array}{l}\text { Lauffenburge } \\
r(2015)^{12}\end{array}$ & $\begin{array}{c}\text { US } \\
\mathrm{HMO} / \text { medicare }\end{array}$ & $\begin{array}{c}\text { Rs } \\
\text { (claims) }\end{array}$ & $\begin{array}{l}\text { D (21070) } \\
\text { W (43865) }\end{array}$ & $\mathrm{AF}$ & $\begin{array}{c}\text { Composite score } \\
\text { Code ICD-9 } \\
\text { hospitalisation }\end{array}$ & Mean 358 days & New users \\
\hline $\begin{array}{l}\text { Beyer- } \\
\text { Westendorf } \\
(2015)^{13}\end{array}$ & $\begin{array}{l}\text { Germany } \\
\text { (Dresden) }\end{array}$ & $\begin{array}{c}\text { Ps } \\
\text { (clinical) }\end{array}$ & $\mathrm{D}(341)$ & $\mathrm{AF}$ & ISTH & 3 months & No comparator \\
\hline $\begin{array}{l}\text { Nishtala } \\
(2015)^{14}\end{array}$ & $\begin{array}{l}\text { New Zealand } \\
\quad>65\end{array}$ & $\begin{array}{c}\text { Rs } \\
\text { (claims) }\end{array}$ & $\begin{array}{l}\mathrm{D}(4835) \\
W(4835)\end{array}$ & $\mathrm{AF}$ & $\begin{array}{l}\text { Any hospitalisation } \\
\text { bleeding }\end{array}$ & Not defined & New users \\
\hline $\begin{array}{l}\text { Hernandez } \\
(2015)^{15}\end{array}$ & $\begin{array}{c}\text { US } \\
\text { Medicare }>65\end{array}$ & $\begin{array}{c}\text { Rs } \\
\text { (claims) }\end{array}$ & $\begin{array}{l}\mathrm{D}(1302) \\
W(8102)\end{array}$ & $\mathrm{AF}$ & $\begin{array}{c}\text { Anatomical site } \\
\text { ICD-9 }\end{array}$ & $\begin{array}{l}\text { Mean } 177 \text { days } \\
\text { Mean } 228 \text { days }\end{array}$ & New users \\
\hline $\begin{array}{l}\text { Yavuz } \\
(2016)^{16}\end{array}$ & Turkey & $\begin{array}{c}\text { Ps } \\
\text { (clinical) }\end{array}$ & $\begin{array}{l}D(381) \\
W(174)\end{array}$ & $\mathrm{AF}$ & Any bleeding & 6 months & \\
\hline $\begin{array}{l}\text { Tamayo } \\
(2015)^{17}\end{array}$ & US & $\begin{array}{c}\text { Rs } \\
\text { (claims) }\end{array}$ & D (27467) & $\mathrm{AF}$ & ISTH & - & No comparator \\
\hline $\begin{array}{l}\text { Laliberte } \\
(2014)^{18}\end{array}$ & $\begin{array}{l}\text { US } \\
\text { HMO }\end{array}$ & $\begin{array}{c}\text { Rs } \\
\text { (claims) }\end{array}$ & $\begin{array}{l}R(3654) \\
W(14616)\end{array}$ & $\mathrm{AF}$ & ISTH & 6 months & $\begin{array}{c}\text { Naïve and non-naïve VKA } \\
\text { users }\end{array}$ \\
\hline $\begin{array}{l}\text { Hecker } \\
(2016)^{19} \\
\end{array}$ & $\begin{array}{l}\text { Germany } \\
\text { (Dresden) }\end{array}$ & $\begin{array}{c}\text { Ps } \\
\text { (clinical) }\end{array}$ & $R(1204)$ & $\mathrm{AF}$ & ISTH & 3 months & No comparator \\
\hline $\begin{array}{l}\text { Camm } \\
(2015)^{20}\end{array}$ & multicenter & $\begin{array}{c}\text { Ps } \\
\text { (clinical) }\end{array}$ & $R(6784)$ & $\mathrm{AF}$ & ISTH & 1 year & No comparator \\
\hline $\begin{array}{l}\text { Ageno } \\
(2015)^{21}\end{array}$ & multicenter & $\begin{array}{c}\text { Ps } \\
\text { (clinical) }\end{array}$ & $\begin{array}{l}R \text { (2619) } \\
W(2149) \\
\end{array}$ & VTE & ISTH & 1 year & \\
\hline $\begin{array}{l}\text { Chang } \\
(2015)^{22}\end{array}$ & US & $\begin{array}{c}\text { Rs } \\
\text { (claims) } \\
\text { HMO }\end{array}$ & $\begin{array}{c}\mathrm{D}(4907) \\
\mathrm{R}(1649) \\
\mathrm{W}(39607) \\
\end{array}$ & $\begin{array}{l}\text { Any indica } \\
\text { tion }\end{array}$ & $\begin{array}{l}\text { Any GI bleeding } \\
\text { ICD-9 hospitalisation }\end{array}$ & - & New users \\
\hline $\begin{array}{l}\text { Maura } \\
(2015)^{23}\end{array}$ & France & $\begin{array}{c}\text { Rs } \\
\text { (claims) }\end{array}$ & $\begin{array}{c}\mathrm{D}(8443) \\
\mathrm{R}(4651) \\
\mathrm{W}(19713) \\
\end{array}$ & $\mathrm{AF}$ & $\begin{array}{l}\text { Bleeding requiring } \\
\text { hospitalisation }\end{array}$ & 3 months & New users \\
\hline $\begin{array}{c}\text { Abraham } \\
(2015)^{24}\end{array}$ & $\begin{array}{c}\text { US } \\
\text { HMO / } \\
\text { Medicaire }\end{array}$ & $\begin{array}{c}\text { Rs } \\
\text { (claims) }\end{array}$ & $\begin{array}{c}\mathrm{D}(8578) \\
R(16253) \\
W(67985)\end{array}$ & $\begin{array}{l}\text { Any indica } \\
\text { tion } \\
A F / \text { non } A F\end{array}$ & Gl bleeding & - & New users \\
\hline Larsen & Denmark & Rs & $\mathrm{A}(6349)$ & $\mathrm{AF}$ & Any bleeding & Mean 2 years & New users \\
\hline
\end{tabular}




\begin{tabular}{|c|c|c|c|c|c|c|c|}
\hline$(2016)^{25}$ & Nationwide & (claims) & $\begin{array}{c}D(12701) \\
R(7192) \\
W(35436)\end{array}$ & & Hospitalisation & & \\
\hline $\operatorname{Lip}_{(2016)^{26}}$ & $\begin{array}{c}\text { US } \\
\text { HMO / } \\
\text { Medicare }\end{array}$ & $\begin{array}{c}\text { Rs } \\
\text { (claims) }\end{array}$ & $\begin{array}{c}A(7438) \\
D(4661) \\
R(17801) \\
W(15461) \\
\end{array}$ & $\mathrm{AF}$ & $\begin{array}{l}\text { Bleeding requiring } \\
\text { hospitalisation } \\
\text { (pooling analysis on } \\
\text { all major bleeding) } \\
\end{array}$ & Mean 160 days & New users \\
\hline $\begin{array}{c}\text { Yao } \\
(2016)^{27}\end{array}$ & $\begin{array}{c}\text { US } \\
\text { HMO / } \\
\text { Medicare }\end{array}$ & $\begin{array}{c}\text { Rs } \\
\text { (claims) }\end{array}$ & $\begin{array}{c}\text { A (15390) } \\
D(28614) \\
R(32350) \\
W(76354)\end{array}$ & $\mathrm{AF}$ & Any bleeding & Not defined & $\begin{array}{c}\text { Naïve and non-naïve VKA } \\
\text { users }\end{array}$ \\
\hline $\begin{array}{l}\text { Staerk } \\
(2016)^{28}\end{array}$ & $\begin{array}{l}\text { Denmark } \\
\text { Nationwide }\end{array}$ & $\begin{array}{c}\text { Rs } \\
\text { (claims) }\end{array}$ & $\begin{array}{c}\text { A (6899) } \\
D(12613) \\
R(5693) \\
W(18094)\end{array}$ & $\mathrm{AF}$ & $\begin{array}{l}\text { Intracranial bleeding } \\
\text { hospitalisation }\end{array}$ & $\begin{array}{l}\text { median 204d } \\
\text { median 386d } \\
\text { median 208d } \\
\text { median 252d }\end{array}$ & New users \\
\hline $\begin{array}{l}\text { Chan } \\
(2016)^{29}\end{array}$ & Taiwan & $\begin{array}{c}\text { Rs } \\
\text { (claims) }\end{array}$ & $\begin{array}{l}\mathrm{D}(5921) \\
\mathrm{R}(3916) \\
W(5251) \\
\end{array}$ & $\mathrm{AF}$ & $\begin{array}{l}\text { Bleeding requiring } \\
\text { hospitalisation }\end{array}$ & End of study date & \\
\hline $\begin{array}{l}\text { Becattini } \\
(2016)^{30}\end{array}$ & $\begin{array}{l}\text { Italy and } \\
\text { Germany }\end{array}$ & $\begin{array}{l}\text { P (clinical) } \\
\text { Case-only }\end{array}$ & $\begin{array}{c}\text { DOAC (191) } \\
\text { W (615) }\end{array}$ & $\begin{array}{l}\text { Any indica } \\
\text { tion }\end{array}$ & ISTH & 1 month & \\
\hline $\begin{array}{l}\text { Graham } \\
(2016)^{31}\end{array}$ & $\begin{array}{c}\text { US } \\
\text { Medicare }>65\end{array}$ & $\mathrm{R}$ (claims) & $\begin{array}{l}D(52250) \\
R(66651)\end{array}$ & $\mathrm{AF}$ & $\begin{array}{c}\text { ISTH except for - } \\
2 \mathrm{~g} / \mathrm{dl} \mathrm{Hb} \\
+ \text { transfusion }\end{array}$ & $\begin{array}{l}15524 \text { py } \\
20199 \text { py }\end{array}$ & New users \\
\hline $\begin{array}{l}\text { Halvorsen } \\
(2017)^{32}\end{array}$ & Norway & $\begin{array}{c}\text { R (claims) } \\
\text { Nationwi } \\
\text { de }\end{array}$ & $\begin{array}{l}\text { W (11427) } \\
D(7925) \\
R(6817) \\
A(6506)\end{array}$ & AF & $\begin{array}{l}\text { ISTH except for - } \\
2 \mathrm{~g} / \mathrm{dl} \mathrm{Hb} \\
\text { Hospital codes }\end{array}$ & Median 6 months & New users \\
\hline $\begin{array}{c}\text { Lai } \\
(2017)^{33} \\
\end{array}$ & Taiwan & $\begin{array}{c}\text { Rs } \\
\text { (claims) } \\
\end{array}$ & $\begin{array}{l}\mathrm{D}(10625) \\
\mathrm{R}(4606)\end{array}$ & $\mathrm{AF}$ & $\begin{array}{c}\mathrm{ICH}, \text { transfusion for } \\
\text { GI bleeding }\end{array}$ & 1 year & No comparator \\
\hline $\begin{array}{c}\mathrm{Xu} \\
(2017)^{34}\end{array}$ & Canada & $\begin{array}{c}\text { Ps } \\
\text { (clinical) } \\
\text { Case only } \\
\text { Hospital- } \\
\text { based }\end{array}$ & $\begin{array}{c}D(245) \\
R(245) \\
A(35) \\
W(1542)\end{array}$ & $\mathrm{AF}$ & ISTH & 1 month & $>66$ years \\
\hline $\begin{array}{c}\mathrm{Li} \\
(2017)^{35}\end{array}$ & $\begin{array}{c}\text { US } \\
\text { HMO / medicare }\end{array}$ & $\begin{array}{c}\text { Rs } \\
\text { (claims) }\end{array}$ & $\begin{array}{l}\text { A (38470) } \\
\text { W (38470) }\end{array}$ & $\mathrm{AF}$ & ISTH & 1 year & New users \\
\hline $\begin{array}{c}\text { Sindet- } \\
\text { Pedersen } \\
(2017)^{36}\end{array}$ & $\begin{array}{l}\text { Denmark } \\
\text { Nationwide }\end{array}$ & $\begin{array}{c}\text { Rs } \\
\text { (claims) }\end{array}$ & $\begin{array}{l}R(5411) \\
W(6907)\end{array}$ & VTE & ISTH & 6 months & \\
\hline $\begin{array}{l}\text { Larsen } \\
(2017)^{37}\end{array}$ & Denmark & $\begin{array}{c}\text { Ps } \\
\text { (clinical) }\end{array}$ & $\begin{array}{l}R(1734) \\
W(2945)\end{array}$ & VTE & $\begin{array}{l}\text { ICH, GI clinical } \\
\text { relevant bleeding }\end{array}$ & 6 months & New users \\
\hline $\begin{array}{l}\text { Helmert } \\
(2017)^{38}\end{array}$ & $\begin{array}{l}\text { Germany, } \\
\text { Dresden }\end{array}$ & $\begin{array}{c}\text { Ps } \\
\text { (clinical) }\end{array}$ & A (514) & $\mathrm{AF}$ & ISTH & 3 months & \\
\hline Abraham & US & Rs & $D(17425)$ & Any indica & Any GI bleeding & Not defined & Head to head comparison \\
\hline
\end{tabular}




\begin{tabular}{|c|c|c|c|c|c|c|c|}
\hline$(2017)^{39}$ & & (claims) & $\begin{array}{l}R(19301) \\
A(6576)\end{array}$ & tion & & & \\
\hline $\begin{array}{l}\text { Amin } \\
(2017)^{40}\end{array}$ & $\begin{array}{c}\text { US } \\
\text { Medicare }>65\end{array}$ & $\begin{array}{c}\mathrm{Rs} \\
\text { (claims) }\end{array}$ & $\begin{array}{l}\text { W (95390) } \\
A(20853) \\
R(53146) \\
D(16743)\end{array}$ & AF & $\begin{array}{l}\text { ISTH } \\
\text { Claim based } \\
\text { algorithm }\end{array}$ & $\begin{array}{l}\text { mean } 199 \mathrm{~d} \\
\text { mean } 171 \mathrm{~d} \\
\text { mean } 204 \mathrm{~d} \\
\text { mean } 196 \mathrm{~d}\end{array}$ & New users \\
\hline $\begin{array}{l}\text { Cangemi } \\
(2017)^{41}\end{array}$ & $\begin{array}{c}\text { US } \\
\text { VA } \\
\text { center }\end{array}$ & $\begin{array}{c}\text { Rs } \\
\text { (claims) } \\
\text { Case only }\end{array}$ & $\begin{array}{c}\text { DOAC } \\
(803) \\
W(6263)\end{array}$ & $\begin{array}{l}\text { Any indica } \\
\text { tion }\end{array}$ & $\begin{array}{c}\text { ISTH } \\
\text { Medical chart review }\end{array}$ & 3 months & All users \\
\hline $\begin{array}{l}\text { Kohsaka } \\
(2017)^{42}\end{array}$ & Japan & $\begin{array}{c}\mathrm{Rs} \\
\text { (claims) }\end{array}$ & $\begin{array}{c}A(5977) \\
D(5090) \\
R(6726) \\
W(17793)\end{array}$ & $\mathrm{AF}$ & $\begin{array}{l}\text { Bleeding requiring } \\
\text { hospitalisation }\end{array}$ & Date of bleeding & New users \\
\hline $\begin{array}{c}\text { Cha } \\
(2017)^{43}\end{array}$ & $\begin{array}{c}\text { Korea } \\
\text { nationwide }\end{array}$ & $\begin{array}{c}\mathrm{Rs} \\
\text { (claims) }\end{array}$ & $\begin{array}{c}A(2189) \\
D(3741) \\
R(5681) \\
W(23222)\end{array}$ & $\mathrm{AF}$ & $\begin{array}{c}\text { ICH } \\
\text { Code ICD-10 } \\
\text { hospitalisation }\end{array}$ & $\begin{array}{l}\text { Mean } 0.4 \mathrm{y} \\
\text { Mean } 1.5 \mathrm{y}\end{array}$ & New users \\
\hline $\begin{array}{l}\text { Denas } \\
(2017)^{44}\end{array}$ & Italy regional & $\begin{array}{c}\mathrm{Rs} \\
\text { (claims) }\end{array}$ & $\begin{array}{c}\text { DOAC } \\
(6923) \\
\text { VKA } \\
(33488) \\
\end{array}$ & $\mathrm{AF}$ & Any bleeding & $\begin{array}{c}6178 \text { y } \\
10611 \text { py }\end{array}$ & New users \\
\hline $\begin{array}{l}\text { Hohnloser } \\
(2017)^{45}\end{array}$ & Germany & $\begin{array}{c}\mathrm{Rs} \\
\text { (claims) }\end{array}$ & $\begin{array}{c}\text { VKA } \\
(16179) \\
A(3633) \\
D(3138) \\
R(12063)\end{array}$ & $\mathrm{AF}$ & $\begin{array}{l}\text { Bleeding requiring } \\
\text { hospitalisation }\end{array}$ & Date of bleeding & New users \\
\hline $\begin{array}{l}\text { Coleman } \\
(2017)^{46}\end{array}$ & Canada & $\begin{array}{c}\mathrm{Rs} \\
\text { (claims) }\end{array}$ & $\begin{array}{l}\text { W (32244) } \\
R(13604)\end{array}$ & VTE & $\begin{array}{l}\text { Bleeding requiring } \\
\text { hospitalisation }\end{array}$ & 1 year & New users \\
\hline $\begin{array}{l}\text { Green } \\
(2018)^{47}\end{array}$ & UK & $\begin{array}{c}\text { Ps } \\
\text { (clinical) } \\
\text { Hospital- } \\
\text { based }\end{array}$ & $\begin{array}{c}\text { W (1771) } \\
\text { DOAC ( 418) }\end{array}$ & Any indication & $\begin{array}{l}\text { ISTH + specific } \\
\text { therapy }\end{array}$ & 1 month & $\begin{array}{l}\text { 3-year prospective } \\
\text { Medical validation }\end{array}$ \\
\hline $\begin{array}{l}\text { Vinogradova } \\
(2018)^{48}\end{array}$ & UK & $\begin{array}{c}\text { Ps } \\
\text { (claims) }\end{array}$ & $\begin{array}{c}\mathrm{W} \\
(132231) \\
D(7744) \\
R(37863) \\
A(18223)\end{array}$ & $\begin{array}{l}\text { Subgroups AF } \\
\text { and no AF }\end{array}$ & $\begin{array}{l}\text { Major bleeding } \\
\text { leading to death } \\
\text { Hospital diagnoses }\end{array}$ & Median 5 to 12 months & New users \\
\hline Our study & France & $\begin{array}{c}\text { Ps } \\
\text { (clinical) } \\
\text { Populatio } \\
\text { n-based }\end{array}$ & $\begin{array}{c}\text { DOAC } \\
(27331) \\
\text { VKA } \\
(20275)\end{array}$ & $\begin{array}{l}\text { Any indica } \\
\text { tion }\end{array}$ & $\begin{array}{l}\text { ISTH except } \\
\text { for }-2 \mathrm{~g} / \mathrm{dl} \mathrm{Hb}\end{array}$ & 1 month and 6 months & $\begin{array}{c}\text { 3-year prospective } \\
\text { Medical validation } \\
\text { New users }\end{array}$ \\
\hline
\end{tabular}

Rs: retrospective; Ps: prospective; D: dabigatran; R: rivaroxaban; A: apixaban; W: warfarin; AF: atrial fibrillation; VTE: venous thromboembolism; ISTH: International Society of Thrombosis and Haemostasis; GI: gastrointestinal; ICH: intracerebral haemorrhage; VKA: vitamin K antagonist; DOAC: direct oral anticoagulant; Hb: hemoglobin; py: person-year. 


\section{Figure 1. Flow-chart}

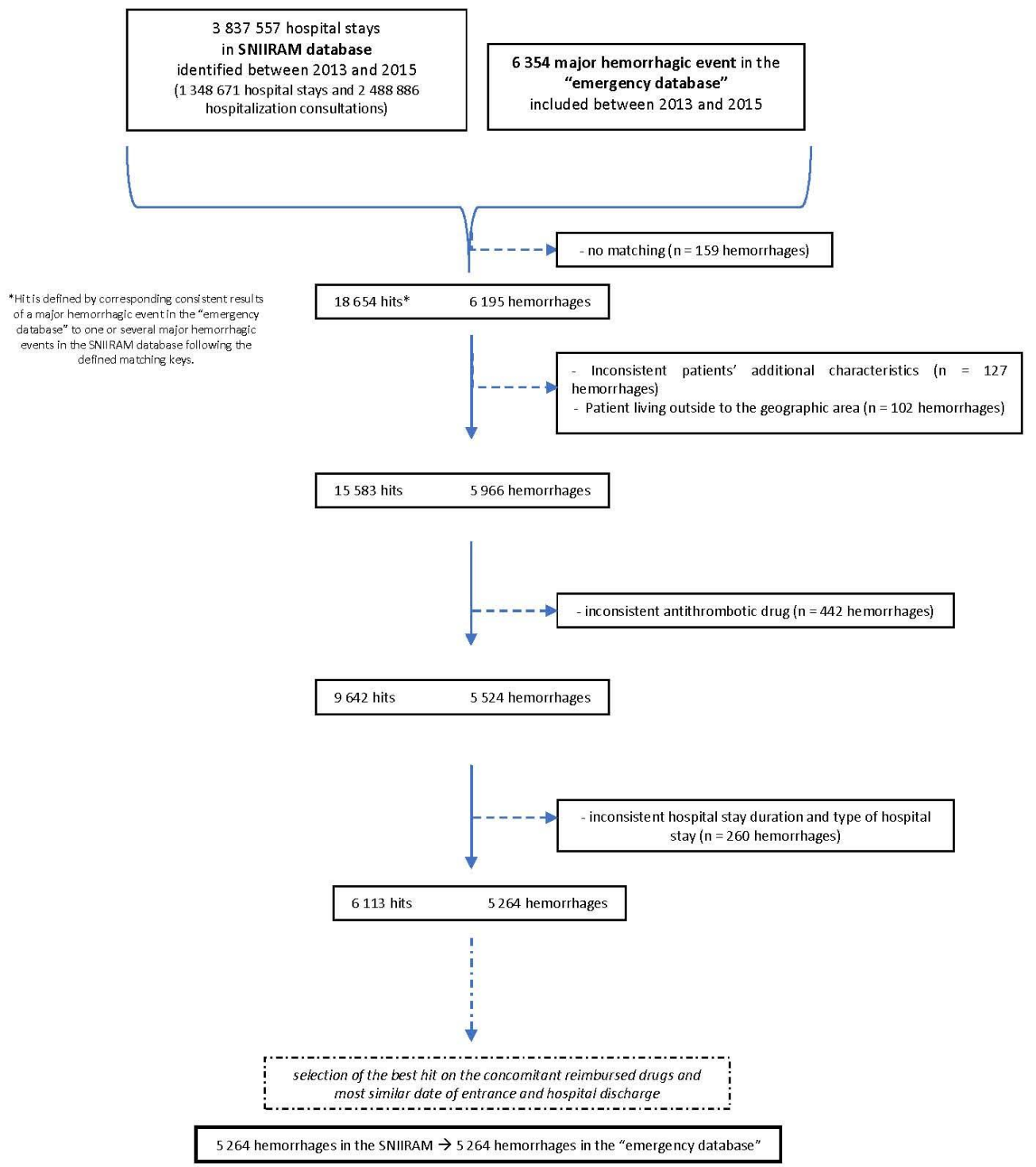

